\title{
Educar, intervir e avaliar em saúde: análise dos itinerários formativos do projeto caminhos do cuidado
}

Educating, intervening and evaluating in health: analysis of the training itineraries of the caminhos do cuidado project

\section{Frederico Viana Machado}

Mestre e Doutor em Psicologia pela UFMG. Professor do Bacharelado em Saúde Coletiva e do Programa de PósGraduação em Saúde Coletiva da Universidade Federal do Rio Grande do Sul. Coordenador do Laboratório de Políticas Públicas, Ações Coletivas e Saúde (LAPPACS/UFRGS). Foi um dos coordenadores do Avalia Caminhos.

\section{Renata Castro Gusmão}

Doutoranda em Educação pela Universidade Federal do Rio Grande do Sul (UFRGS). Mestra em Saúde Coletiva pela UFRGS. Foi coordenadora macrorregional do projeto Caminhos do Cuidado. Fez parte da equipe nacional da Avaliação do Caminhos do Cuidado e trabalhou como Orientadora de aprendizagem no Curso de Especialização em Acompanhamento, Monitoramento e Avaliação na Educação em Saúde Coletiva.

\section{Franceli Francki dos Santos}

Mestra em Saúde Coletiva pela UFRGS. Atuou como coordenadora macrorregional do Caminhos do Cuidado e compôs a equipe de avaliação do Caminhos do Cuidado.

\section{Pedro Augusto Papini}

Participou da construção do material pedagógico do Caminhos do Cuidado, foi coordenador macrorregional do Caminhos do Cuidado e compôs a equipe de avaliação do Caminhos do Cuidado. Atualmente é doutorando em Psicologia Social e Institucional pela UFRGS e psicólogo clínico.

\section{Anna Letícia Ventre}

Compôs a Coordenação Macrorregional e a equipe de avaliação nacional do projeto Caminhos do Cuidado. Atuou como Orientadora de Aprendizagem no AvaliaCaminhos. Mestra pelo Programa de Psicanálise: Clínica e Cultura (UFRGS). Atualmente é doutoranda em Psicologia Social e Institucional pela UFRGS e psicóloga clínica.

\section{Stefanie Kulpa}

Graduação em Pedagogia, especialização em Educação Permanente em Saúde e mestrado em Educação pela Universidade Federal do Rio Grande do Sul (2000).

\section{Resumo}

Este artigo apresenta parte dos resultados da avaliação nacional do Projeto Caminhos do Cuidado, guiada por uma matriz avaliativa composta por quatro dimensões - Gerencial, Política, Itinerários Formativos e Cenários do Cuidado. Discutiremos especificamente a dimensão Itinerários Formativos, que agrupa as percepções das práticas de educação, aprendizagem e metodologias pedagógicas desta formação direcionada à Agentes Comunitários em Saúde e Técnicos de Enfermagem das Estratégias de Saúde da Família do Brasil. A metodologia inclui um questionário quantitativo que foi respondido por 1151 sujeitos, entrevistas e rodas de conversa. Aplicamos a análise de conteúdo em dados provenientes de 78 rodas de conversa, ocorridas nas 27 Unidades Federativas do Brasil, e 33 entrevistas com participantes do Projeto. Os resultados se dividem em três partes: 1) Arranjos, materiais e estratégias pedagógicas; 2) Seleção formativa de tutores; 3) Educação à distância na formação de tutores e orientadores. A avaliação demonstra que as singularidades e as diversidades do território nacional fizeram parte dos Itinerários Formativos. A estratégia de ancorar a maior parte do curso à experiência dos trabalhadores no território foi identificada como elemento privilegiado para uma aprendizagem significativa, nos moldes da educação popular em saúde e da educação permanente em saúde. A utilização a educação à distância foi negativamente avaliada pelos participantes, destacando-se como dificuldades a baixa motivação e as dificuldades de interação. 0 
Caminhos do Cuidado mostrou que são possíveis processos educativos e avaliativos em larga escala e que contemplem a diversidade de saberes, recriando-se pela experiência de cada território e fortalecendo-se em redes.

Palavras-chave: Avaliação em Saúde; Educação Permanente em Saúde; Estratégia da Saúde da Família; Experiência; Saúde Mental.

\section{Abstract}

This article presents part of the results of the national evaluation of the Caminhos do Cuidado Project, guided by an evaluation matrix composed of four dimensions - Management, Politics, Formative Itineraries and Care Scenarios. We will specifically discuss the Formative Itineraries dimension, which groups the perceptions of the practices of education, learning and pedagogical methodologies of this training directed to Community Health Agents and Nursing Technicians of Family Health Strategies in Brazil. The methodology includes a quantitative questionnaire that was answered by 1151 subjects, interviews and conversation circles. We applied

\section{Introdução}

Este artigo apresenta os resultados da avaliação nacional da formação em saúde mental (crack, álcool e outras drogas) do Projeto Caminhos do Cuidado, enfocando a dimensão Itinerários Formativos - que agrupa as práticas de educação, aprendizagem e metodologias pedagógicas. $\mathrm{Na}$ avaliação nacional do Caminhos do Cuidado ${ }^{1}$, operou-se com uma matriz avaliativa composta por quatro dimensões: Política, Gerencial, Itinerários Formativos e Cenários do Cuidado². Analisaremos os resultados da dimensão Itinerários Formativos, apostando em elementos éticos, estéticos e políticos como a construção coletiva, a escuta do outro e a horizontalização do content analysis to data from 78 conversation circles, which took place in the 27 Federative Units in Brazil, and 33 interviews. The results are divided into three parts: 1) Arrangements, materials and pedagogical strategies; 2) Formative selection of tutors; 3) Distance learning in the training of tutors and advisors. The evaluation shows that the singularities and diversities of the national territory were part of the Formative Itineraries. The strategy of anchoring most of the course to the experience of workers in the territory was identified as a privileged element for meaningful learning, along the lines of popular health education and permanent health education. The use of distance education was negatively assessed by the participants, with low motivation and interaction difficulties standing out as difficulties. The Paths of Care showed that large-scale educational and evaluative processes are possible and that contemplate the diversity of knowledge, recreating themselves through the experience of each territory and strengthening themselves in networks.

Keywords: Health Evaluation; Permanent Education in Health; Family Health Strategy; Experience; Mental health.

saber. Esses elementos fundamentam os conceitos que nortearam o processo pedagógico, tais como Educação Permanente em Saúde, Educação Popular em Saúde ${ }^{4}$ e Experiência ${ }^{5}$.

O Caminhos do Cuidado teve início em julho de 2013 a partir da parceria com o Ministério da Saúde por meio da Secretaria de Gestão do Trabalho e Educação em Saúde (SGTES); do Instituto de Comunicação e Informação Científica e Tecnológica em Saúde da Fundação Oswaldo Cruz (Icict/FIOCRUZ), do Grupo Hospitalar Conceição (GHC), e da Universidade Federal do Rio Grande do Sul (UFRGS). As 
Escolas Técnicas do SUS (ETSUS) foram parceiras fundamentais, tanto na execução como na avaliação. O Projeto foi pensado e planejado para os profissionais de nível médio, auxiliares e técnicos de enfermagem (Atenf) e agentes comunitários de saúde (ACS). Tinha como meta propiciar formação em saúde mental, álcool e outras drogas a todos os ACS e ao menos um Atenf por equipe da Estratégia de Saúde da Família (ESF) do país. Uma meta desafiadora, considerando a extensão e diversidade dos territórios brasileiros.

O Caminhos do Cuidado surge como uma das frentes de trabalho do programa Crack é possível vencer, voltada para o setor saúde, e teve como metas: 1) Ofertar 1260 vagas de facilitadores nas temáticas de Saúde Mental, crack, álcool e outras drogas; 2) Ofertar 290.760 vagas de formação para Agentes Comunitários de Saúde (ACS), Auxiliares e Técnicos em Enfermagem (ATENF) da Estratégia Saúde da Família, em temáticas de Saúde Mental, com ênfase em crack, álcool e outras drogas e; 3) Desenvolver metodologia de educação permanente para trabalhadores de saúde no campo da saúde mental.

Em dezembro de 2015, o projeto ultrapassa as metas previstas, com a formação de 237.263 ACS e ATENF e 2.118 facilitadores ${ }^{6}$. Inicia-se, então, a última fase do projeto, que consistia no desenvolvimento de atividades de educação permanente, que incluía a avaliação nacional do Caminhos do Cuidado. O Programa de Avaliação Institucional Educativa AvaliaCaminhos - construiu uma metodologia de avaliação interventiva, formativa, descentralizada e participativa. Teve a experiência como palavraguia, buscou descrever e analisar as experiências enunciadas por quem participou do Caminhos do Cuidado.

A experiência, na perspectiva de Jorge Larrosa, nos instiga ao exercício de reconhecer aquilo que nos acontece, que nos afeta, que permanece em cada um/a. Para o autor, "o saber da experiência se dá na relação entre o conhecimento e a vida humana, [...] é uma espécie de mediação entre ambos $^{\prime 5: 26}$. O conceito de experiência dialoga com os preceitos da Educação Popular em Saúde, se a entendermos como o ensino calcado nos saberes constituídos nos territórios, tomando como ponto de partida para a construção de conhecimento os saberes prévios dos educandos ${ }^{7}$. O conceito de experiência também dialoga com a Educação Permanente em Saúde, pois busca transversalizar pensamento, experimentação e implicação com o trabalho ${ }^{3}$.

Os resultados desta avaliação buscam expressar o saber da experiência de quem vivenciou o Caminhos do Cuidado. A experiência era trazida para os cenários de formação, compondo com o roteiro previsto, dando sentido, criando itinerários formativos conforme a prática de cada território. O objetivo aqui é analisarmos o roteiro previsto, os desvios e/ou invenções que traziam como pressupostos teórico-metodológicos a construção coletiva, a escuta do outro e a horizontalização do saber. 
Para compreender o saber da experiência, Larrosa propõe uma ruptura com os pares "ciência/técnica" e "teoria/prática" e sugere "pensar a educação a partir do par experiência/sentido" 5:20. "No saber da experiência não se trata na verdade do que são as coisas, mas do sentido ou do sem-sentido do que

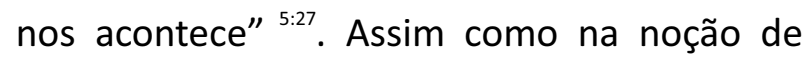
experiência de Larrosa, a Educação Popular em Saúde propõe uma quebra na dicotomização dos saberes científicos e dos saberes do território, pois são caminhos que se complementam? .

A dimensão Itinerários Formativos, objeto deste artigo, levantava questões sobre: o material didático; as metodologias; a formação presencial e a formação-seletiva de tutores e orientadores; o uso das tecnologias de Educação à Distância (EaD); as ações com suas invenções nos territórios. Também questionou as especificidades regionais e o conteúdo (linguagem, compreensão, organização) dos materiais em relação aos objetivos do curso, a sustentabilidade para as ações do tutor, os critérios de avaliação, a efetividade da construção de conhecimentos, a adequação da carga horária, a participação dos diferentes atores, as metodologias didáticas (dinâmicas de grupo; rodas de conversa; avaliação; acesso, ambientação e exploração da Comunidade de Práticas - a aplicação da EaD), narrativas, estudos de caso, uso de fotografias, o trabalho final, as adaptações, especificidades e estratégias locais ${ }^{2,6,1}$.

Dividimos os resultados e a discussão em três seções. A primeira diz respeito à construção da proposta pedagógica; a segunda aos materiais e estratégias pedagógicas; a terceira à seleção formativa de tutores e orientadores (levando em conta as complexidades de se construir um processo de educação permanente utilizando ferramentas de educação à distância). Nas considerações finais apontamos no itinerário formativo do Caminhos do Cuidado a potência de transformação do cotidiano de trabalho a partir do encontro com a alteridade, que opera uma transformação do olhar e uma qualificação do cuidado em saúde mental.

\section{Método: do plantio à colheita}

O AvaliaCaminhos foi composto de duas ações relacionadas: 1) Avaliação Nacional do Caminhos do Cuidado, de abordagem qualitativa e quantitativa, guiada por uma Matriz Avaliativa, construída coletivamente por atores que participaram de sua execução; 2) Curso de Especialização em Acompanhamento, Monitoramento, Avaliação na Educação em Saúde Coletiva. As duas ações mantinham estreita relação, aqui apresentaremos a metodologia utilizada na ação 1. Como se trata de um projeto amplo, em razão do espaço apresentaremos apenas os pontos metodológicos principais. A metodologia utilizada pelo AvaliaCaminhos foi discutida detalhadamente em artigo anterior ${ }^{8}$.

O AvaliaCaminhos abriu o diálogo sobre as consequências do processo formativo do Caminhos do Cuidado nas políticas públicas, na organização dos serviços e no processo de trabalho nos territórios, na educação em saúde e 
na atenção à saúde. Um percurso que foi orientado, tanto em sua execução, como em sua avaliação, pela Educação Permanente em Saúde:

Educação Permanente em Saúde é sua porosidade à realidade mutável e mutante das ações e dos serviços de saúde; é sua ligação política com a formação de perfis profissionais e de serviços, a introdução de mecanismos, espaços e temas que geram autoanálise, autogestão, implicação, mudança institucional, enfim, pensamento (disruptura com instituídos, fórmulas ou modelos) e experimentação (em contexto, em afetividade - sendo afetado pela realidade/afecção) ${ }^{3}$.

Nesta perspectiva, a avaliação foi construída para ser: interventiva, na produção de efeitos entre quem avalia e quem é avaliado; formativa, por possibilitar a construção de novos saberes; descentralizada, buscando a diversidade dos territórios, dentro das possibilidades disponíveis; e participativa, por incluir as diversas perspectivas das pessoas envolvidas em todo o processo de construção, desenvolvimento e avaliação do Caminhos do Cuidado. Neste cenário, a avaliação não assume um caráter somativo, seu objetivo não era aprovar ou reprovar, mas expressar efeitos possíveis em um determinado contexto, afinada com uma perspectiva avaliativa de quarta geração ${ }^{9}$.

Esta avaliação se inspira nas avaliações de quarta geração, não apenas por ser participativa e formativa, mas por se voltar aos interessados buscando construir mecanismos para a análise dos atores e sua capacidade de melhorar os serviços de saúde ${ }^{10}$. Incorpora uma concepção de aprendizagem voltada para invenção, tendo o inacabamento como marca, estando em permanente processo de a prendizage $m, m$ as também $d e$ desaprendizagem ${ }^{11}$.

No processo avaliativo trabalhamos com o termo colheita de dados, e não coleta de dados, para expressar que as informações vieram de um solo que foi semeado e adubado por quem o conhece e o cuida. Os dados foram plantados, selecionados e colhidos de acordo com o solo de cada território, efeitos de um plantio e cuidados específicos. Seus frutos, advém da diversidade de experiências produzidas, não carregam a pretensão de representar ou mensurar impactos, tamanha a complexidade deste objetivo, mas sim, expressar efeitos e mudanças potenciais que mais se destacaram.

Como já mencionado, a avaliação foi orientada por uma Matriz Avaliativa construída coletivamente por diferentes olhares e perspectivas de quem participou do Caminhos do Cuidado e por um Painel de Especialistas, composto por profissionais com larga trajetória na Saúde Mental, Redução de Danos, avaliação em saúde e processos pedagógicos ${ }^{2}$. A Matriz apresenta quatro dimensões interrelacionadas, dentre as quais trabalharemos a Itinerários Formativos, cujos questionamentos foram apresentados na introdução.

Para a colheita de dados, a avaliação contou com um instrumento quantitativo - um 
questionário - e instrumentos qualitativos roteiro para entrevistas e rodas de conversa. $\mathrm{O}$ questionário e o roteiro semiestruturado foram pré-testados e revisados antes de serem aplicados. Ambos foram pensados de forma articulada, embora tenham sido aplicados separadamente. Este artigo toma como eixo central os dados qualitativos. Os dados produzidos pelo questionário serão úteis apenas para dimensionar alguns resultados da análise qualitativa. Ambos foram construídos considerando as questões da Matriz Avaliativa da seguinte forma:

- Avaliação quantitativa: o questionárioavaliativo foi construído na plataforma FormSUS, cujo link enviamos eletronicamente para alunas e alunos concluintes do Caminhos do Cuidado - no período de dezembro de 2016 a abril de 2017. Para o cálculo de tamanho da amostra, consideramos: o número total de alunos/as concluintes, confiança de 99\%, margem de erro de 5\% e proporção de $50 \%$ para cada resposta do questionário. Assim, chegou-se ao tamanho mínimo da amostra de 662 sujeitos. Obtivemos 1151 questionários respondidos. Tendo em vista que o questionário seria enviado por e-mail e a taxa de resposta para esse tipo de estratégia esperada seria de 10\%, foram selecionados 6.642 sujeitos. 0 planejamento amostral considerou a cobertura dos municípios de grande $e$ pequeno porte, seguindo a abrangência do Caminhos do Cuidado, distribuídas nos 27 Estados. Para isso, partimos do banco de dados nacional do Caminhos do Cuidado para verificar qual o tamanho populacional dos municípios a serem buscados para a amostragem. Em uma planilha com todos as/os formadas/os no Brasil, verificamos que os quartis dos totais populacionais foram: Q1 = 18.397, $Q 2=44.428$ e $Q 3=205.533$. Sendo assim, dividimos os municípios em quatro grupos, sendo que o menor tamanho populacional foi determinado pelo menor município e o maior tamanho populacional foi determinado pelo maior município de formadas/os.

- Avaliação Qualitativa - entrevistas e rodas de conversa: utilizamos um roteiro semiestruturado - guiado conforme as realidades locais e a dinâmica dialógica, que fazia com que perguntas fossem inseridas ou adaptadas. A equipe realizou, transcreveu e analisou 78 rodas de conversa, de modo que todas as 27 Unidades Federativas do Brasil estão contempladas com pelo menos duas rodas de conversa em municípios distintos, conforme o planejado, envolvendo aproximadamente 717 ACS/ATENF. Também contamos com 33 encontros, em entrevistas ou rodas, com as/aos tutoras/es, que também foram transcritas e analisadas. Para identificar a origem dos dados neste artigo usaremos $R C$ seguido do nome da cidade e sigla do estado para indicar trechos das 
falas de ACS e ATEnf que ocorreram nas Rodas de Conversa. As demais referências indicam a função da pessoa no projeto.

Para o tratamento e análise dos dados qualitativos orientamo-nos pela análise de conteúdo ${ }^{12}$, com as seguintes etapas: 1 ) leitura flutuante dos dados: no qual cada membro da equipe de análise (18 pessoas) leu parte do material textual e grifou os pontos que chamaram mais atenção, distribuindo os trechos nos eixos da Matriz Avaliativa; 2) Categorização: Após a leitura o material foi categorizado nos marcadores da Matriz, seguimos lendo exaustivamente cada um dos agrupamentos de dados e organizando-os em temas e argumentos; 3) Triangulação de pesquisadores: Cada membro da equipe apresentou suas categorias e conjuntamente lemos as partes mais relevantes do material categorizado, revisando os descritores de cada categoria e reagrupando suas definições quando foi possível ${ }^{13}$. O material textual foi tratado no QSR International's NVivo 11 e quando termos importantes para a análise demandavam uma investigação comparativa mais precisa, a localização de conteúdo foi estratégica para contemplar as diferentes perspectivas pelas quais um determinado tema era abordado.

\section{Resultados e discussão}

\section{A construção da proposta pedagógica}

A avaliação trouxe à cena os desafios que envolveram o processo de formação, que partia do cotidiano e das práticas vivenciadas pelos
ACS e ATEnf nos territórios e do protagonismo desses atores na busca de melhores alternativas de cuidado em saúde mental, especialmente aqueles usuários em situações de uso prejudicial de drogas. Para a elaboração da proposta pedagógica e do material didático, foi constituído um grupo multidisciplinar a fim de contemplar as premissas do Caminhos do Cuidado. Este grupo elaborou uma metodologia pedagógica que permitia abertura para se conectar ao mundo do trabalho dos alunos, dando lugar aos problemas e necessidades identificadas no processo de trabalho nos territórios, no acolhimento aos usuários, na mobilização e articulação da rede de apoio social e comunitária.

É importante salientar que no período desta escrita vivenciamos no Brasil um redirecionamento das políticas públicas em âmbito federal, sobretudo, referente à Saúde Mental e à ética do cuidado ofertado na temática das drogas. Esse redirecionamento é entendido também como um desmonte de políticas baseadas na Reforma Psiquiátrica e nos princípios do SUS e, tal como aponta Delgado $^{14}$, é posto em marcha a partir de 2016. No período que o Projeto foi executado e avaliado, já existia um cenário de tensionamento político, no qual estes retrocessos já estavam postos como uma ameaça. A matriz curricular do Caminhos do Cuidado teve como base os princípios do SUS, a Política Nacional de Saúde Mental, Política de Atenção Básica e a Política de Atenção Integral aos usuários de álcool e outras drogas. 
Contemplou os seguintes aspectos:

a) A apropriação do processo de reforma psiquiátrica, da política de saúde mental com ênfase na rede de atenção psicossocial, com vistas à produção do cuidado, a reintegração social e da cidadania das pessoas usuárias de álcool e outras drogas;

b) A discussão e construção do papel do ACS e ATEnf para o cuidado em saúde mental, conforme a especificidade de cada território, qualificando o olhar e a escuta para dar visibilidade à questão das drogas;

c) A ampliação da caixa de ferramentas do ACS e ATEnf para o cuidado em saúde mental, atuação na rede de atenção e na construção de territórios de paz.

A Matriz Curricular foi como enquadramos a avaliação da reverberação dos objetivos nos territórios. A proposta pedagógica do projeto ganhou existência em um modo peculiar de produção de movimentos de aprendizagem que envolveram alunas, tutores, orientadoras, consultores, educadoras e vários outros atores. A formação dos ACS e ATENF reverberou também nas redes e equipes, assim como ressoou em si, no cotidiano em que estão inseridos/as.

\section{Materiais e estratégias pedagógicas}

A Metodologia, ou o "jeito de ensinar", aparece nas narrativas como um diferencial do Caminhos do Cuidado, destacando elementos como o protagonismo dos alunos, as trocas de experiências, a centralidade dos problemas do território, a delicadeza ao abordar temas polêmicos, a horizontalidade nas relações pedagógicas, o exercício da alteridade, entre outros. A metodologia do projeto foi vista como positivamente "diferente" de outras capacitações oferecidas aos trabalhadores da saúde. Com perspectivas distintas, todos os sujeitos escutados pela avaliação associam a metodologia à sua capacidade de se relacionar com as necessidades do cotidiano e como as produções pedagógicas exigiam uma participação ativa em ações ou construções territoriais:

A própria proposta da capacitação já era diferente das outras capacitações que eles viveram (...) isso produziu necessidade real de mudança neles... (Orientadora de Aprendizagem).

Acho que dá pra emendar na questão que a gente sempre falava; como a parte pedagógica desse projeto foi boa. (...) Os agentes depois diziam assim: 'a gente não vem aqui, a pessoa blá-blá-blá, a gente anota e sai e nem entendeu muito bem para que tem que fazer isso' - Não era esse o papel deles [dos alunos]. Eles tinham que construir (Tutora).

A construção de conhecimentos fundamentada no trabalho, nos moldes da educação permanente em saúde ${ }^{3}$, foi apontada como um elemento central, tendo em vista que a proposta pedagógica trazia para a cena suas experiências: "Uma coisa que me chamou a atenção foi a grande aceitação, por parte dos alunos, da metodologia, que proporcionava que eles participassem" (Coordenadora Pedagógica). A experiência dando um sentido à 
formação, esta característica participativa da metodologia gerou horizontalidade e proximidade nas ações pedagógicas, momentos de escuta, de valorização da palavra, como aparece nas narrativas que seguem:

O que fez a diferença também é que os Agentes Comunitários diziam como eles se sentiam compreendidos. (...) as pessoas nos [outros] cursos não sabiam nem o que eles faziam, quais eram as suas práticas... Eu acho que isso faz diferença. Porque tu sabia qual era o caminho deles e a gente podia compor junto (Tutora).

O que eu achei bom no curso foi a opinião de todos, todos foram escutados, cada um dava a sua opinião e juntava tudo, chegava num consenso e pronto, todos respeitaram as opiniões de todos (RCMacaíba-RN).

Alicerçado no protagonismo das/os alunas/os, o processo formativo propôs-se a pensar outros jeitos de ensinar-aprender. A transversalidade das relações pedagógicas abriu a possibilidade de trocas e uma construção conjunta do saber, o que aproxima o projeto da proposta da educação popular freireana ${ }^{4}$ do processo de aprendizagem ser conduzido pela problematização do cotidiano: "Foi todo dinâmico, a gente instruía mais do que era instruído e isso direcionava o dia a dia do curso" (RC Campo Grande-MT). A oportunidade de deslocar-se do lugar do mestre para construir junto com o/a aluno/a apareceu como uma potência, como traz a fala da tutora:

Eu esperava que o conteúdo fosse dado, linha por linha, o professor explica e deu... Daí quando eu entrei no Caminhos entendi que não era esse o processo, que ele ia ser construído junto, que ia ter muitas reflexões... então, eu acho que isso foi a diferença. Eu tenho lido Paulo Freire e vem bem ao encontro de tudo, a parte pedagógica, de que nada é imposto, mas é construído, refletido. Isso é importante (Tutora).

Tanto os dados quantitativos como os qualitativos trouxeram à cena a importância da abertura de espaços de diálogo, de troca e ampliação de experiências. $57 \%$ dos respondentes do questionário destacaram como ponto positivo do curso o incentivo a trazer experiências pessoais e do trabalho para os encontros. De todos os respondentes, apenas 3\% não gostou do formato das aulas. $\mathrm{Na}$ etapa qualitativa a criação de espaços de diálogo teve destaque, o que explicita a capacidade da metodologia do curso de produzir espaços de Educação Permanente. Um processo de aprendizagem que não se adapta ao mundo externo, mas que está implicado na invenção do próprio mundo ${ }^{11}$ :

Foi de suma importância porque teve o contato nosso. Porque apesar de nós trabalharmos juntos há tantos anos, a gente não se vê todos os dias, porque cada qual tá na sua área. Então esse curso proporcionou um contato, um diálogo de situação diferente, porque nós trabalhamos no mesmo trabalho mas vivenciamos coisas diferentes (Toritama-PE).

Eu acho que foi o único curso que a gente foi agraciado que a gente pode conviver mais com os ACS da região, e a troca de ideias, porque a gente tem a nossa realidade e a realidade delas é diferente. Então foi de muita valia também a troca de experiências com as outras colegas ( $R C$ 
Soledade-RS).

O encontro com o cotidiano de trabalho e com a multiplicidade das formas com que os problemas sociais apareceram nos espaços do curso contribuiu para a construção conjunta da estratégia didática e se mostrou uma boa resposta para os desafios formativos sobre temas complexos e delicados (tais como saúde mental, álcool e outras drogas) ${ }^{15}$, como reconhece o educador citado abaixo. A tutora, citada a seguir, reforça esta percepção argumentando que o "jeito de ensinar" contribuiu para tornar leve um tema duro.

Isso permitiu também a gente entrar em contato com a complexidade de se produzir em ato na saúde. No campo da saúde mental, especificamente, (...) lidar com o processo de adoecimento das pessoas... é de uma complexidade! E aí tivemos vários desafios, enquanto trabalhadores de saúde, para ter contato com isso. Como capacitar as pessoas para se deparar com esta realidade complexa em todos os sentidos? (...) Que desafio é esse? (Educador).

Pra mim foi um divisor de águas... Toda a parte da pedagogia, eu acho que foi impressionante... Como o conteúdo fica sem ser duro. E nas aulas a gente aprendia muito essa coisa da leveza, que é onde eu me encontrei mesmo... Então, hoje eu tento fazer isso, ser um pouco mais leve, mas com responsabilidade, com liberdade (Tutora).

As formações propuseram a qualificação dos processos de trabalho repensando as ações de ensino apoiadas nas narrativas da vida real, trocadas e refletidas ao longo da formação. Fato que, segundo relato de algumas tutoras, favoreceram discussões sobre a alteridade, na proposição de colocar-se na situação do outro, um exercício que contribuiu com uma formação profissional mais respeitosa em relação ao cuidado em saúde mental:

Mesmo quando o assunto era Redução de Danos, quando falava em RD para eles [no início era]: tinha que parar de beber, ou tinha que parar de usar drogas... (...) aí a gente puxava os outros exemplos da clínica, do diabético que não pode comer açúcar (...) Então, a gente começou a fazer essas associações e aí eles perceberam o quanto é difícil, a pessoa que tem ansiedade, que come com compulsão, como é difícil... É fácil tu dizer (..) não pode! E aí, quando eles começaram fazer essa inversão de papéis e se colocar no lugar de cada usuário, é que eles começaram a mudar esse olhar (Tutora).

No encontro com as narrativas das experiências, percebemos que participar de um processo pedagógico, como foi o Caminhos do Cuidado, ultrapassou os conteúdos e cenários programados. Reverberando também em espaços que não estavam diretamente relacionados aos objetivos do curso, mas que dizem respeito a um "jeito de ensinar":

Para mim o maior impacto (é) o quanto essa metodologia cabe nas minhas aulas (...). Vem do Caminhos do Cuidado, algo que foi brutal, que continua reverberando em mim (Educador).

As dinâmicas, eu até peguei essas dinâmicas, coloquei dentro da associação que organiza, botei lá na igreja (RC Lauro de Freitas - BA).

A proposta pedagógica dos encontros presenciais utilizava dinâmicas, dramatizações, 
rodas de conversa e filmes com a finalidade de ampliar a interação entre os participantes e sua sensibilidade em relação ao tema. Sobre essas propostas, $38 \%$ dos respondentes do questionário consideram como destaque a possibilidade de fazer uso da criatividade nos encontros utilizando música, teatro, cordéis, paródias, poesia, vídeos, etc. Essa experiência pode ser qualificada pela motivação que os alunos expressaram nas Rodas de Conversa:

A gente voltava pra sala de aula e parecia aqueles meninos da alfabetização, doido pra contar o que fez (risos) [Todas concordaram] (RC Cabedelo-PB).

Praticando a gente assimila mais. Teve a cartolina no chão, na construção do mapa... do território (RC Riachuelo-SE).

Os vídeos também apareceram como mobilizadores de afetos, ilustrando vivências e questões referentes à saúde mental. Muitos alunos trouxeram situações e exemplos que foram enriquecedores para o processo de aprendizagem do grupo. Alguns, inclusive, compartilharam vivências próprias com o uso de drogas. Segundo um Tutor, "foi interessante eles poderem falar e se colocar no lugar de uma pessoa que passou por, ou que ainda passa, e aí se perceber o quão difícil é trabalhar com o outro com essa situação".

Encontramos falas que mostram a flexibilidade do material didático, que permitiu a adaptação às discussões propostas e, por apresentar linguagem acessível, se mostrou adaptável a cada contexto, o que favorece utilizá-lo em seus ambientes de trabalho, mas também em situações que ultrapassam a formação e o cenário de trabalho:

Ele te dá a oportunidade de navegar para além dele. Ele é um apoiador da sala, mas ele proporciona ir além dele (Coordenação Estadual).

Guardo ela [apostila] como um livro que você precisa pro dia-a-dia, pro resto de sua vida, porque lá tem tudo (RC Barbalha - CE).

Até hoje eu guardo o meu [tirou o livro da bolsa e mostrou] qualquer dúvida eu venho aqui, qualquer trabalho que eu quero desenvolver na equipe lá na minha área eu venho aqui. Sabe, isso ajuda muito, com certeza (RC Macapá- AP).

O meu material serviu para além do curso. Até lá me casa meus filhos fizeram leitura. Eu acabei trazendo para cá (RC Montes Claros - MG).

O questionário identifica que a maioria dos respondentes $(72 \%)$ consideraram que 0 material utilizado na formação ajudou a compreender o cuidado em saúde mental, álcool e outras drogas, $46 \%$ consideraram a linguagem apropriada e 35\% consideraram que - material estava adequado para a sua realidade local. Dos respondentes, apenas $2 \%$ consideraram que o material não colaborou para compreender o cuidado em saúde mental, crack, álcool e outras drogas.

\section{Seleção formativa de tutores e orientadores}

Uma das apostas do projeto foi que o processo seletivo dos tutores e orientadores também teria uma dimensão formativa e que envolvia um número significativo de pessoas (dois mil 
setecentos e sessenta e um trabalhadores de saúde que passaram por formação de orientador e tutor ao longo do projeto). Esta perspectiva ia ao encontro das diretrizes pedagógicas que consideravam os sujeitos em constante construção, tal como nos sugere a Educação Popular em Saúde ${ }^{4}$ a Educação Permanente em Saúde ${ }^{3}$. O processo formativo deveria se iniciar com a seleção e seguir durante todo o projeto por meio da estratégias de educação à distância.

A seleção formativa presencial dos tutores tinha como mote a experimentação do material pedagógico. Os candidatos viam todo o material pedagógico, sendo possível não apenas entrar em contato com os conteúdos programados, mas também vivenciar a metodologia de trabalho e relacioná-la às suas próprias experiências. Esta formação experiencial foi importante pois os conteúdos e a sua forma de operacionalização exigia implicação dos tutores. Em artigo que trata especificamente da formação de tutores do Caminhos do Cuidado, Papini e Tittoni ${ }^{16}$ argumentam que a implicação neste processo pedagógico era necessária pois o curso abordava temas delicados, relacionados muitas vezes com experiências pessoais dos participantes quanto à saúde mental e ao uso de drogas. Nesse sentido, a formação demandava a reflexão sobre preconceitos sobre o cuidado em saúde mental e o cuidado de pessoas com problemas relacionados ao uso de drogas.

A avaliação demonstrou a efetividade da seleção formativa de tutores e orientadores, na medida em que o desenvolvimento pessoal foi associado à estratégia de vivenciar criticamente a proposta pedagógica antes de colocá-la em prática nos territórios. Os atores entrevistados valorizaram a seleção formativa e processual para a potencialização de sua atuação como tutores/orientadores. Ao abordarem a aprendizagem de novas práticas pedagógicas, os tutores entrevistados destacaram na seleção formativa o deslocamento do professor do lugar do saber incluindo a escuta como inerente à prática pedagógica e colocando a experiência como agenciadora do pensamento e o sujeito e seu cotidiano como centro do processo educativo:

Acho que foi a grande questão, esta possibilidade do tutor poder vivenciar daquilo que se pretendia que ele desenvolvesse com o aluno, a centralidade do aluno, a oportunidade da palavra, a reflexão sobre seu próprio cotidiano, que as técnicas, de uma certa forma, oportunizavam (Tutor).

Visualizar tudo o que eu vivenciei lá foi muito interessante, porque fazia volta com a prática. (...) Quando botamos o pé no chão, ali as coisas vieram surgindo, as oficinas lá facilitaram muito. As vivências que a gente teve lá, pra mim, facilitaram a construção (Tutor).

A "oportunidade de vivenciar" foi destacada pelos orientadores, que não conduziram o processo educativo presencial, mas apoiaram os tutores nesta tarefa:

Foi muito importante para mim a capacitação inicial, viver a dinâmica... Porque não é fácil - não foi fácil nem para mim - viver uma capacitação em que tenho que me expor. Me fez sentir que isso 
também poderia ser uma dificuldade do outro, o que também me servia de subsídio para trabalhar essas questões com o tutor (Orientadora).

A avaliação nos mostra que a estratégia pedagógica utilizada na seleção formativa dialogou com os conceitos de Educação Permanente em Saúde e com a base freireana da Educação Popular em saúde. Seguindo o conceito de Larrosa ${ }^{5}$, a formação de tutores relacionou o conhecimento com o mundo vivido, deslocou dicotomias, como ciência e técnica, teoria e prática, articulando experiências e a construção singular de sentido. Este processo foi fundamental para consolidar a implicação dos tutores no projeto.

\section{Educação à distância na formação de tutores e orientadores}

Realizado o processo formativo/seletivo, foi ofertada para os tutores selecionados um Ambiente Virtual de Aprendizagem (AVA) de apoio e comunicação entre Tutores/as e Orientadores/as e entre Orientadores/as e Educadores/as. O ensino à distância cresce como uma proposta de oferta pedagógica pela possibilidade de dinamizar redes de aprendizado, porém ainda existem entraves para garantir a qualidade do ensino, da participação e da avaliação ${ }^{17}$. Além de exigir conhecimentos de informática, também exige novas técnicas pedagógicas, não apenas uma transposição das técnicas e relações presenciais, "essas relações passariam a ser baseadas na colaboração e na co-construção do conhecimento, ou seja, horizontalizar-se-iam"18.
As/os tutores selecionados e os orientadores de aprendizagem tinham pouca experiência no ensino à distância e não houve uma estratégia formativa mais intensa sobre o uso destas ferramentas. A formação presencial de tutores e orientadores permitiu apenas uma apresentação e um breve experimentação das ferramentas da plataforma virtual, o que limitou as interações nas comunidades de práticas. Embora conhecedores das áreas de saúde mental e atenção básica, foram pouco motivados e encontraram dificuldades na formulação de atividade e no uso das ferramentas; Além disto, também foram mencionadas hierarquias e fluxos institucionais que limitavam as possibilidades de interação.

Eu demorei para saber o que podia fazer na comunidade, (...) não tinha prática. Vários não tinham. $\mathrm{O}$ ambiente virtual por si já é difícil, pelo acesso e pela dificuldade de comunicação, até porque tinham hierarquias que se estabeleceram dentro do próprio pedagógico, quem se relaciona com quem virtualmente (Apoio Pedagógico).

Eu confesso que usei pouco essa plataforma. Até porque, no início surgiam dúvidas, mas com o passar do tempo as coisas iam se repetindo... e aí não estimulou muito não. Eu realmente confesso que não fiquei muito estimulada com essa ferramenta (Tutora).

Entre as fragilidades relacionadas para o uso da EaD, estão as dificuldades no manejo da plataforma e na constituição de um espaço virtual mais informativo do que interativo e colaborativo, adicionado ao acúmulo de atividades que a formação presencial exigia: 
A minha educadora alimentava aquele espaço com artigos e textos atuais da política de redução de danos, por exemplo. Um espaço mais de colher informação que de trocas. Eu não conseguia provocar uma discussão, eventualmente isso acontecia (Orientadora).

De um lado o orientador que tinha que cobrar, motivar. Do outro o tutor que alegava falta de tempo para realizar as atividades... (Orientadora).

Das fragilidades no processo de formação à distância, identificamos como principal dificuldade a ativação de processos de Educação Permanente entre os pares de comunidade de prática, associados a problemas que limitavam a interação. De um modo geral, os entrevistados avaliaram negativamente o uso do $\mathrm{EaD}$, e as avaliações positivas foram residuais. As dificuldades vivenciadas nesse processo indicam que o EAD demandava estratégias pedagógicas e apoio para o trabalho do facilitador no ambiente virtual que não foram ocorreram ou não foram efetivas na formação dos tutores. Como argumentam Batista e Pinheiro ${ }^{19}$, para que a EaD funcione é preciso garantir "bons materiais de estudo, uma plataforma que permita interação efetiva entre todos os participantes, bem como profissionais qualificados (tutores) para esse trabalho tão importante, tendo em vista que eles incentivarão seus alunos a serem autônomos e disciplinados para o estudo"19:1.

Tendo em vista que as experiências mais expressivas do ensino à distância ainda são recentes e pouco estudadas, e que a grande maioria dos investimentos nesta área trabalham em uma perspectiva vinculada a propostas pedagógicas autoinstrucionais, a superação das formas de ensino tradicionais se torna ainda mais relevante ${ }^{20}$. Tendo em vista a importância crescente da EaD para promover ações formativas e avaliativas mais ágeis e efetivas, a avaliação do Caminhos do Cuidado nos mostra a urgência de investimentos em inclusão e alfabetização digital para trabalhadores da saúde, bem como da atualização das estratégias e concepções pedagógicas para este novo universo.

\section{Considerações Finais}

O Caminhos do Cuidado, tanto em sua execução, como em sua avaliação, apostou na experiência como potência do processo educativo e para dar sentido ao referencial proposto e à construção coletiva dos itinerários formativos. Se destacam a valorização dos saberes locais nas atividades de ensino e a abertura para as singularidades, que Paulo Freire já nos ensinava. Como já argumentam Santos e Ferla ${ }^{21}$ :

A formação do Caminhos do Cuidado reiterou a necessidade de se repensar novas práticas educativas para os profissionais de saúde, uma vez que a educação tradicional já não corresponde mais às expectativas e necessidades de profissionais submetidos a processos formativos de qualquer natureza ${ }^{21: 836}$.

O "jeito de ensinar" apareceu como um destaque para a motivação dos alunos:

Começo a achar que é uma perda de tempo 
qualquer capacitação que não seja assim (Educadora)";

“A metodologia definiu todo o curso. Se fosse só repasse de informações, seria extremamente cansativo, mas sentia vontade de ir para o curso (Montes Claros - MG).

A metodologia do Caminhos do Cuidado permitiu que questões individuais pudessem ser elaboradas, o que promoveu efeitos singulares e permitiu que cada participante acessasse seu repertório de vivências profissionais e pessoais para melhor conectar com os conteúdos e capacidades do curso.

"Foi tirar uma escama de peixe do olho"; "antes eu não ia naquela casa, agora vou, faço questão de ir"; "me sento na praça e fico escrevendo e observando (...) só para me familiarizar com eles". Falas como estas, extraídas nas rodas de conversa com ACS, compõem as narrativas sobre a experiência que nos permitem dizer que o Caminhos do Cuidado desembaçou os olhos e os corações promovendo um encontro com a alteridade, uma pequena fagulha de humanização no cuidado. Expressam a potência de trazer a experiência para cena e de um "jeito de ensinar", também falam de um "como olhar", "como cuidar", da potência do vínculo para iniciar um cuidado.

O Caminhos do Cuidado foi um curso que formou 237.175 (Brasil, 2016) profissionais. Uma formação em uma escala tão grande correria o risco de cair em padronizações que a distanciariam da realidade dos trabalhadores e das necessidades sociais em saúde relacionadas ao tema. Mesmo diante de um número tão grande de participantes, a avaliação demonstra que as singularidades de cada local e as diversidades do território nacional foram amplamente consideradas e incluídas como parte dos Itinerários Formativos. A estratégia de ancorar a maior parte do curso à experiência dos trabalhadores no território foi identificada positivamente pelos diversos procedimentos metodológicos desta avaliação, de modo a constituir o elemento privilegiado para uma aprendizagem significativa, nos moldes da educação popular em saúde e da educação permanente em saúde.

A articulação entre intervenção e formação buscou sentido exatamente no trabalho cotidiano, nas práticas de cuidado, transbordando os cenários previstos durante a formação, criando novas redes apoio. A avaliação evidenciou o quão potente foi a aposta no encontro, no sentar em roda e colocar a palavra para circular, fazendo do cotidiano aprendizado: "pensar a educação a partir do par experiência/sentido", tal como argumenta Larrosa (2016, p.16).

Ao percorrermos os dados da avaliação do Caminhos do Cuidado, observamos o quanto metodologias participativas são necessárias para pensarmos educação e avaliação, pela flexibilidade de transformá-las com o cotidiano. Atualmente, o Brasil encontra-se em um momento de grande tensionamento político e social, no qual direitos adquiridos encontram- 
se em risco. Entre os desmontes sofridos após 2016, Delgado (2019) discute a alteração da Política Nacional de Atenção Básica (PNAB), modificando os parâmetros populacionais e dispensando a obrigatoriedade da presença do agente comunitário de saúde nas equipes de saúde da família, e argumenta que isto fragiliza os cenários aqui trabalhados, colocando em risco a qualidade e o acesso ao cuidado.

Santos $^{22}$ considera que há que se democratizar a democracia. Inclui-se o pensar os processos educativos, de modo que contemplem uma maior diversidade de conhecimentos - não apenas acadêmicos mas também da experiência incluindo os saberes daqueles que de modo geral são excluídos, invisibilizados. O Caminhos do Cuidado mostrou que são possíveis processos educativos e avaliativos em larga escala e que contemplem a diversidade de saberes, recriandose pela experiência de cada território e fortalecendo-se em redes. Foi a experiência que deu sentido ao conteúdo previsto; a Educação Permanente em Saúde e a Educação Popular em Saúde são ferramentas que transbordam a formação e a avaliação, reverberando nas diversas esferas da vida, animadas pela abertura da surpresa do encontro e de um ponto de interrogação diante das certezas das realidades embrutecidas pela dor e pelo sofrimento. Finalizamos com a frase de um participante do Caminhos do Cuidado que buscava palavras para avaliar o processo educativo: 0 curso fez nosso

\section{Referências}

1. Brasil. Ministério da Saúde. Instituto de Comunicação e Informação Científica e Tecnológica em Saúde/FIOCRUZ. Relatório Final: AvaliaCaminhos. Rio do Janeiro: FIOCRUZ, 2017.

2. Observatório do Cuidado. Matriz Avaliativa. Disponível em: https://www.observatoriodocuidado.org/matriz-avaliativa. Acessado em 12/05/2019

${ }^{3 .}$ Ceccim, RB. Educação Permanente em Saúde: desafio ambicioso e necessário. Interface - Comunic, Saúde. Set-fev.2005. 9(16): 161-77.

4.Freire, P; Nogueira, A. Que fazer: teoria e prática em educação popular. Vozes: Petrópolis, RJ, 1993.

${ }^{5}$ Larrosa, J. Notas sobre a experiência e o saber de experiência. Revista Brasileira de Educação. Jan-Abr 2002. 19:20-28.

${ }^{6 .}$ Brasil. Ministério da Saúde. Secretaria de Gestão do Trabalho e da Educação na Saúde. Caminhos do Cuidado Observatório: Relatório 2016. Rio do Janeiro: FIOCRUZ, 2016.

${ }^{7}$ Gomes LB; Merhy EE. Compreendendo a educação popular em saúde: um estudo na literatura brasileira. Cad. Saúde Pública, Rio de Janeiro, jan, 2011, 27(1):7-18.

${ }^{8 .}$ Gusmao, RC; Papini, PA; Santos, F; Ventre, A; Pinto, EEP; Ruaro, GCG; Rodrigues, E; Machado, FV. Notas metodológicas de uma avaliação formativa, interventiva e participativa: a experiência do AvaliaCaminhos. Cadernos do Cuidado. 2017 1(1): 26-40.

9. Akerman, M. \& Furtado, J. (Orgs). Práticas de avaliação em saúde no Brasil: diálogos. Porto Alegre: Editora Rede Unida, 2015.

${ }^{10}$ Kantorski, L; Wetzel, C; Olschowsky, A; Jardim, V; Bielemann, V; Schneider, J. Avaliação de quarta geração - contribuições metodológicas para avaliação de serviços de saúde mental. Interface: Comunicação, Saúde e Educação. Out./dez. 2009. 13(31): 343-55.

${ }^{11}$ Kastrup, V. Ensinar e aprender: falando de tubos, potes e redes. Arte na Escola. São Paulo. Dez. 2005. 40: 6-7.

12. Minayo, MCS. O desafio do conhecimento: pesquisa qualitativa em saúde. São Paulo: Hucitec, 2006. 
${ }^{13 .}$ Creswell, J. Research Design: Qualitative, Quantitative, and Mixed Methods Approaches. London: SAGE, 2003.

${ }^{14}$ Delgado, PG. Reforma psiquiátrica: estratégias para resistir ao desmonte. Trab. educ. saúde. Jan 2019. 17(2):1-4.

15. Papini, PA; Santos, FF; Pinto, EEP; Ruaro, GCG; Machado, FV; Santos, LD; Ventre, AL; Gusmão, RC. Notas sobre as Reduções de Danos no Caminhos do Cuidado. Cadernos do Cuidado. 2017. 1(2):1-17.

16. Papini, P; Tittoni, J. Em busca do silêncio e da infâmia nas drogas: percursos de experiência, escrita e pesquisa. Athenea Digital. 2017. 17(1): 43-56.

${ }^{17 .}$ Cruz, Jr; Lima, Dcp. Trajetória da educação a distância no Brasil: políticas, programas e ações nos últimos 40 anos. Jornal de Políticas Educacionais. Abril de 2019. 13(13): 1-19.

${ }^{18 .}$ Gomes, LF. EAD no Brasil: Perspectivas e Desafios. Avaliação. mar. 2013. 18(1):13-22.

${ }^{19 .}$ Batista, M; Pinheiro, C. Contribuições para desmistificação da educação a distância. Revista de Pesquisa Interdisciplinar, 2019, 4:1-11.

${ }^{20 .}$ Silva, A; Santos, A; Cortez, E; Cordeiro, B. Limites e possibilidades do ensino à distância (EaD) na educação permanente em saúde: revisão integrativa. Ciênc. saúde coletiva. Abril 2015, 20(4):1099-1107.

21. Santos, FF; Ferla, A. Saúde Mental e Atenção Básica no cuidado aos usuários de álcool e outras drogas. Interface (Botucatu). 2017; 21(63):833-44.

${ }^{22 .}$ Santos, BS. (org.). Democratizar a democracia - Os caminhos da democracia participativa. Porto: Afrontamento, 2003. 